\title{
Genotype - phenotype correlation in an adolescent girl with pathogenic PPARy genetic variation that caused severe hypertriglyceridemia and early onset type 2 diabetes
}

\author{
Ana Gutierrez Alvarez', \\ Naomi Yachelevich', \\ Brenda Kohn', \\ Preneet Cheema Brar ${ }^{1}$
}

'Division of Endocrinology and Diabetes, Department of Pediatrics, New York University Grossman School of Medicine, New York, NY, USA

${ }^{2}$ Division of Clinical Genetics, Department of Pediatrics, New York University Grossman School of Medicine, New York, NY, USA
Received: 10 March, 2021

Revised: 26 April, 2021

Accepted: 25 May, 2021

Address for correspondence:

Preneet Cheema Brar

Division of Endocrinology and Diabetes, Department of Pediatrics, New York University Grossman School of Medicine, 150 East 32nd street, L2, New York, NY 10016, USA Email: preneet.brar@nyumc.org https://orcid.org/0000-0002-60658328
Severe hypertriglyceridemia (HTG) (>885 mg/dL) can be caused by familial partial lipodystrophy type 3 (FPLD3), an autosomal dominant disorder caused by loss of function of the peroxisome proliferator-activated receptor gamma (PPARG), characterized by abnormal distribution of fat and metabolic derangements. This case reports a 16-year-old female (body mass index, $23.5 \mathrm{~kg} / \mathrm{m}^{2}$ ) hospitalized twice for pancreatitis (triglycerides [TG] level $>2,200 \mathrm{mg} / \mathrm{dL}$ ). Her treatment management included bowel rest, insulin infusion, and plasmapheresis. A low-fat diet with 10 $\mathrm{g}$ of fat daily and $160 \mathrm{mg}$ of fenofibrate daily decreased fasting TG to $411 \mathrm{mg} / \mathrm{dL}$ (range, $0-149 \mathrm{mg} / \mathrm{dL}$ ). The patient had a normal leptin level. Panel testing of genes that impact TG metabolism revealed a known pathogenic variant in the PPARG gene (c.452A>G p.Tyr151Cys). A second variant detected in this gene, c.1003G >C (p.Val335Leu), is considered benign. Her glycosylated hemoglobin of $6.6 \%$ and 2-hour oral glucose tolerance test confirmed type 2 diabetes mellitus (T2DM). This study reports the earliest detection of T2DM in an adolescent with a pathogenic variant of PPARG. PPARG-related FPLD3 should be considered in lean children that present with severe HTG and insulin resistance, and subsequent treatment with proliferator-activated receptor gamma agonists, specifically thiazolidinediones, should be considered.

Keywords: PPARY mutation, Hypertriglyceridemia, Pancreatitis, Type 2 diabetes mellitus, Pancreatectomy

\section{Highlights}

- Severe hypertriglyceridemia (HTG) can be caused by familial partial lipodystrophies (FPLD).

- PPARG gene mutation causes FPLD type 3 characterized by abnormal fat distribution and severe HTG.

- Type 2 diabetes can occur early, in their teens, in a patients PPARG related mutation.

\section{Introduction}

Familial partial lipodystrophy (FPLD) is a heterogeneous genetic disorder that affects an estimated one in one million people and is characterized by abnormal regional distribution of adipose tissue. Six types of FPLD have been described: FPLD type 1 (Kobberling lipodystrophy); FPLD type 2, the most common type, is a defect in the lamin A/C (LMNA) gene (Dunnigan variety $)^{11}$; FPLD type 3 causes a defect in the peroxisome proliferator-activated 
receptor gamma gene (PPARG- FPLD3 $)^{2}$; FPLD type 4 is related to pathogenic variants in the PLIN1 gene that codes for perilipin $1^{3)}$; FPLD type 5 is autosomal recessive and related to pathogenic variants in the CIDEC gene; and FPLD type 6 is caused by the LIPE (lipase E, hormone sensitive type) gene. While loss of adipose tissue (lipoatrophy) is the hallmark characteristic, clinical features include cutaneous (restrictive dermatopathy and alopecia) and skeletal anomalies (late closure of cranial sutures, bird-like progeroid facies). Metabolic aberrations include insulin resistance, diabetes, hypertriglyceridemia (HTG), low high-density lipoprotein (HDL) cholesterol, hepatic steatosis, and increased risk for cardiovascular disease. In most studies describing the metabolic aberrations in FPLD, HTG usually precedes glucose abnormalities, though insulin resistance is universal. FPLD can be clinically diagnosed based on loss of adipose tissue and documentation of abnormal fat distribution using whole body magnetic resonance imaging.

Peroxisome proliferator-activated receptor gamma (PPARy) is a nuclear hormone receptor in the superfamily of ligand activated transcription factors $(\alpha, \beta / \delta$ and $\mathrm{Y})$. PPARy is a critical key regulator of adipogenesis, the process in which mesenchymal stem cells change morphology, undergo clonal expansion, and insulin receptors are formed in mature adipocytes. ${ }^{4,5)}$ PPARy forms a heterodimer with retinoid $X$ receptors, enabling its binding to the target to induce differentiation of preadipocytes to adipocytes, and it regulates several transcription factors that control adipocyte differentiation, resulting in small insulin sensitive adipocytes. It also upregulates adiponectin to improve insulin sensitivity. ${ }^{5)}$ The first description of heterozygous, dominant loss-of-function human mutations of PPARy was in 1999, and research has indicated that loss of PPARy function impacts both adipocyte differentiation and function. ${ }^{2)}$

\section{Case report}

A 16-year-old Hispanic female was hospitalized and received intensive care due to 2 pancreatitis episodes that occurred 1.5 months apart. On her first admission, her weight was 65.2 $\mathrm{kg}(82 \%, z$-score $=0.93)$, height $163.4 \mathrm{~cm}(54 \%, z$-score $=0.10)$ and body mass index (BMI) was $23.5 \mathrm{~kg} / \mathrm{m}^{2}$. She presented with a 2-day history of abdominal pain, emesis, and anorexia. Computed tomography (CT) scans showed no appendicitis, extensive peripancreatic fluid with extension into the right pararenal space, and paracolic gutter. She was afebrile but tachycardic up to the 120 s. Table 1 shows laboratory results at baseline, during admission, and after discharge. On admission, lipase was mildly elevated at $113 \mathrm{U} / \mathrm{L}$ (reference range, 8-78 $\mathrm{U} / \mathrm{L})$ and amylase was $123 \mathrm{U} / \mathrm{L}(25-125 \mathrm{U} / \mathrm{L})$, which was at the high end of normal. White blood cell (WBC) count was $19,000 / \mu \mathrm{L}$ (range, 4,500-11,000/ $\mu \mathrm{L}$ ), hemoglobin $(\mathrm{Hb})$ $13.5 \mathrm{~g} / \mathrm{dL}(2-16 \mathrm{~g} / \mathrm{dL})$, hematocrit (Hct) 37.1\% (36\%-46\%) with a normal coagulation profile (prothrombin time, 10.5 seconds; international normalized ratio, 1.02). Urine analysis results were $1+$ ketones, $2+$ bilirubin, $3+$ protein, $1+$ nitrites, $1+$ leukocyte esterase, and 2-5 WBCs. Her sodium was 132 $\mathrm{mmol} / \mathrm{L}$, with mild lactic acidosis (bicarbonate of $21 \mathrm{mmol} /$ $\mathrm{L}$ and lactate of $4.5 \mathrm{mmol} / \mathrm{L}$ ). Her liver function test results were unremarkable. Eight hours later, her lipase and amylase normalized to 70 and $88 \mathrm{U} / \mathrm{L}$, respectively. After 18 hours off of oral feeding and intravenous fluids, her triglycerides (TG) were reported as $1,920 \mathrm{mg} / \mathrm{dL}$ with a total cholesterol (TC) of $43 \mathrm{mg} / \mathrm{dL}$ with low HDL of $30 \mathrm{mg} / \mathrm{dL}$. One day later, her TG rose to $>2,200 \mathrm{mg} / \mathrm{dL}$, TC of $426 \mathrm{mg} / \mathrm{dL}$, and HDL of $34 \mathrm{mg} /$ $\mathrm{dL}$. Abdominal ultrasound revealed hepatomegaly and steatosis. No gall stones were identified. She was discharged 3 days later with recommendations of a low-fat diet and follow-up with a gastroenterologist after symptomatic improvement when she was able to tolerate oral feeding.

She presented for her second admission 42 days later with recurrent pancreatitis. She had a pulse of 108 beats per minute and blood pressure (BP) of 144/70 $\mathrm{mmHg}$. She was started on pain medications, IV ciprofloxacin, metronidazole, hydration, and bowel rest. On admission, her lipase was 3 times higher than normal, amylase was normal, TG were $>1,100 \mathrm{mg} / \mathrm{dL}$ and increased to $>2,200 \mathrm{mg} / \mathrm{dL}$, TC was $1,200 \mathrm{mg} / \mathrm{dL}$, and HDL was $>5 \mathrm{mg} / \mathrm{dL}$. Laboratory test results indicated a 17,000/ $\mu \mathrm{L}, \mathrm{Hb} 12 \mathrm{~g} / \mathrm{L}$, and Hct 33.4\%. Erythrocyte sedimentation rate was $20 \mathrm{~mm} / \mathrm{hr}$. Thyroid function tests were normal, and

Table 1. Laboratory results on baseline and during admissions (1 and 2) and follow-up appointment

\begin{tabular}{|c|c|c|c|c|c|}
\hline Variable & Baseline \#1 & During admission \#1 & Baseline \#2 & During admission \#2 & 3-Month follow-up \\
\hline Amylase (U/L) & 126 & 88 & ND & ND & 90 \\
\hline Lipase (U/L) & 113 & 70 & 100 & $244,83,70$ & 24 \\
\hline $\mathrm{TG}(\mathrm{mg} / \mathrm{dL})$ & $>1,100$ & $>2,200$ & 1,100 & $2200,1148,1394,1148,1198,522,424,426,651$ & 411 \\
\hline Glucose (mg/dL) & 119 & ND & 95 & $173,162,157,159,147$ & 162 \\
\hline Insulin $(\mu \mathrm{U} / \mathrm{mL})$ & ND & ND & ND & ND & 501 \\
\hline HbA1c (\%) & ND & ND & $4.80 \%$ & ND & 6.6 \\
\hline $\mathrm{HCO}_{3}(\mathrm{mmol} / \mathrm{L})$ & 21 & ND & 23 & $15.3,12.7$ & 25 \\
\hline Lactate (mmol/L) & 4.5 & ND & 4.5 & 2.8 & 2.3 \\
\hline $\mathrm{ALT}(\mathrm{U} / \mathrm{L})$ & $<5$ & 16 & 50 & 36 & 34 \\
\hline
\end{tabular}

TG, triglycerides; $\mathrm{HbA} 1 \mathrm{c}$, glycosylated hemoglobin; $\mathrm{HCO}_{3}$, bicarbonate; $\mathrm{ALT}$, alanine aminotransferase; $\mathrm{ND}$, not done.

Reference values: TG, 0-149 mg/dL; amylase, 25-125 U/L; lipase, 8-78 U/L; lactate, 0-1.9 mmol/L; HCO 3 , 22-29 mmol/L; glucose, 70-100 $\mathrm{mg} / \mathrm{dL}$; insulin, 3-20 $\mathrm{UU} / \mathrm{mL} ; \mathrm{HbA1c}$, 4\%-5.7\%; AST, 5-34 U/L; ALT, 0-55 U/L. 
glycosylated hemoglobin (HbA1c) was 4.8\%. Random blood sugar measurements during her admission were elevated and ranged between $137-173 \mathrm{mg} / \mathrm{dL}$. Elevated BP was attributed to pain, fluid overload, and hypernatremia and was treated with diuretics. A CT scan showed edema of the pancreas with no necrosis/calcifications. Insulin drip was started at $0.1 \mathrm{U} / \mathrm{kg} / \mathrm{hr}$. Three days into admission, plasmapheresis was performed and then repeated twice (30 and 50 hours after her first round) to assess worsening symptoms of epigastric pain, tachycardia, and metabolic acidosis ( $\mathrm{PH}, 7.25 ; \mathrm{PCO}_{2} \mathrm{mmHg}, 29 ; \mathrm{PO}_{2} \mathrm{mmHg}$, 44; $\left.\mathrm{HCO}_{3}-\mathrm{meq} / \mathrm{L}, 12.7\right)$. After 10 days, the patient was discharged on a strict low-fat diet of $10 \mathrm{~g}$ of fat daily, omega 3 acid ethyl esters (brand name Lovaza, $2 \mathrm{~g}$ ), and fenofibrate $160 \mathrm{mg}$ daily, which she tolerated well with no reported side effects.

Secondary causes including obesity, metabolic syndrome, and medication effects (e.g., glucocorticoids, anabolic steroids, retinoids, and diuretics) for HTG were ruled out.

Panel testing of genes involved in lipid metabolism was assayed on an Illumina MiSeq platform and VarSeq CNV (GRCh37) through the Blackburn Cardiovascular Genetics Laboratory at the Roberts Research Institute. This panel includes genes involved in lipoprotein metabolism: $L P L$, APOC2, APOA5, APOE, APOC3, LMF1, and GP1HBP1; intracellular carbohydrate metabolism: GCKR and GPD1; intracellular lipid metabolism: CREB3L3; as well as $P P A R G$, a regulator of adipocyte differentiation. Results of $L P L$, APOC2, APOA5, LMF1, GPIHBP1, GCKR, CREB3L3, GPD1, $A P O E$, and $A P O C 3$ gene analyses were normal. Two variants, c. $452 \mathrm{~A}>\mathrm{G}$ (p.Tyr151Cys) and c.1003G>C (p.Val335Leu), were reported in the PPARG gene. The $c .452 \mathrm{~A}>\mathrm{G}$ (transcript reference NM_015869.4, hg37 reference) p.Tyr151Cys variant in exon 3 was previously reported as pathogenic in the Human Gene mutation database. ${ }^{6-8)}$ The second variant, c.1003G $>C$ (p.Val335Leu), is rare (minor allele frequency 0.01\%). Current interpretations of this mutation in ClinVar are conflicting and assessments include "variant of uncertain significance," "likely benign," and "benign," as defined by the American College of Medical Genetics and Genomics and the Association for Molecular Pathology. ${ }^{9)}$ A family history was collected, and the following were noted: the father was $90 \mathrm{~kg}$ and denied hypertension and diabetes; the mother lived in the Dominican Republic and a had history of abnormal cholesterol, although no test results were available for review. The patient had not lived with her mother since 6 years of age. No significant family history was determined from other family members on either side of the family with regard to body fat distribution, diabetes, or lipid profile. Because the parents refused genetic testing, we could not ascertain whether the mutation was de novo versus an inherited variant.

A more detailed physical exam was conducted after the patient's genetic test results were received; based on her history, the fat loss in the distal part of her upper and lower extremities and slight excess of subcutaneous fat in the face and neck were consistent with lipodystrophy (family refused photographs and no skin fold thickness measurements were performed). There was no evidence of hirsutism. She had mild acanthosis nigricans on her neck and axillae. No eruptive xanthomas, xanthelasma, or lipemia retinalis were noted on exam. The patient had regular menstrual periods with no clinical concerns for polycystic ovaries. After 4 weeks of dietary fat restriction with fenofibarte and Lovaza, her fasting TG were $411 \mathrm{mg} / \mathrm{dL}$, HDL, $28 \mathrm{mg} / \mathrm{dL}$ normal $[\mathrm{N}]>39 \mathrm{mg} / \mathrm{dL}$ ), low-density lipoprotein, $84 \mathrm{mg} / \mathrm{dL}(\mathrm{N}$ $<100 \mathrm{mg} / \mathrm{dL}), \mathrm{TC}, 151 \mathrm{mg} / \mathrm{dL}(\mathrm{N}<170 \mathrm{mg} / \mathrm{dL})$, and creatinine kinase was $90 \mathrm{IU} / \mathrm{L}(\mathrm{N}, 29-168 \mathrm{U} / \mathrm{L})$. Follicle stimulating hormone was $5 \mathrm{mIU} / \mathrm{mL}$ (N, 3-17 follicular phase), luteinizing hormone was $2.0 \mathrm{mIU} / \mathrm{mL}$ (N, 8-89 follicular phase), estradiol was $14.9 \mathrm{pg} / \mathrm{mL}(\mathrm{N}, 2-266)$, total testosterone was $5.0 \mathrm{ng} / \mathrm{dL}$ (N, 9-58), and dehydroepiandrosterone sulfate $142 \mu \mathrm{g} / \mathrm{dL}(\mathrm{N}$, 63-373), which excluded polycystic ovary syndrome. She had a normal leptin level of $1.6 \mathrm{ng} / \mathrm{mL}$ (no established reference for adolescents). To evaluate the effect of the identified pathogenic variant in PPARG on glucose metabolism, as well as a history of elevated random sugars during her second admission, a 2-hour oral glucose tolerance test was performed using 75-g oral glucose. Her fasting glucose was $99 \mathrm{mg} / \mathrm{dL}$, and her 2-hour postprandial glucose was $220 \mathrm{mg} / \mathrm{dL}$. She had hyperinsulinemia: her insulin was 52 and $123 \mu \mathrm{U} / \mathrm{mL}$ at fasting and at 2 hours, respectively. Her $\mathrm{HbAlc}$ was $6.6 \%$. These results confirmed type 2 diabetes mellitus (T2DM), and we recommended that she begin taking the PPARy agonist pioglitazone.

\section{Discussion}

Our patient was found to harbor a previously reported pathogenic variant in the PPARG gene, a rare cause of HTG. This diagnosis was made possible because of the genetic testing performed at the Blackburn Cardiovascular Genetics Laboratory, which exceeded the testing for the 5 known genes that cause familial homozygous HTG (LPL, APOC2, APOA5, $L M F 1, G P I H B P 1)$. Broekema et al. ${ }^{10)}$ described a total of 97 FPLD3 associated PPARG variants, of which 14 children and adolescents presented with clinical phenotypic loss of adipose tissue, HTG and/or pancreatitis, and noted that symptoms usually presented around puberty, although lipoatrophy was described in an infant (compound heterozygote) and a 3-yearold male toddler. Majithia et al. ${ }^{11)}$ described 3 females with $P P A R G$ pathogenic variants with impaired glucose tolerance and/or type 2 diabetes (Table 2 compares the metabolic profiles of these patients with our patient).

Our patient presented with severe HTG confirmed by TG $>885 \mathrm{mg} / \mathrm{dL}$ and $10 \mathrm{mmol} / \mathrm{L}^{12)}$ Conservative treatment using bowel rest and hydration can lower TG level by $70 \%$ in patients with extremely high TG $(>4,000 \mathrm{mg} / \mathrm{dL}){ }^{13)}$ Plasmapharesis can acutely reduce the TG level by $50 \%-80 \%$ and can be instrumental if the patient has lactic acidosis, acute respiratory distress, and/or shock. This rationale was considered for this patient and 3 rounds of plasmapheresis were applied due to her metabolic/clinical decompensation. Insulin activates lipoprotein lipase, which facilitates TG degradation and should be used as a continuous infusion because it is easier to titrate along with 
Table 2. Clinical and metabolic data of 3 patients and our patient

\begin{tabular}{lcccccccccc}
\hline Patient No. & $\begin{array}{c}\text { Age } \\
(\mathrm{yr})\end{array}$ & $\begin{array}{c}\text { Weight } \\
(\mathrm{kg})\end{array}$ & $\begin{array}{c}\mathrm{TG} \\
(\mathrm{mg} / \mathrm{dL})\end{array}$ & $\mathrm{HDL}$ & $\begin{array}{c}\text { Glucose } \\
(\mathrm{mg} / \mathrm{dL})\end{array}$ & $\begin{array}{c}\text { Insulin } \\
(\mu \mathrm{U} / \mathrm{mL})\end{array}$ & $\begin{array}{c}\text { HbA1c } \\
(\%)\end{array}$ & IFG/type 2 diabetes & NASH & Hypertension \\
\hline Patient \#1 & 16 & 48 & 1,168 & 15 & 131 & 6 & 7.2 & Yes & Yes & Yes \\
Patient \#2 & 13 & 44 & 150 & 46 & 66 & 23 & 6.2 & Yes & Yes & Yes \\
Patient \#3 & 15 & 98 & 965 & 31 & 95 & 44 & 8.2 & Yes & Yes & Yes \\
Patient \#4 & 16 & 65 & 1,100 & 30 & 119 & 501 & 6.6 & Yes & Yes & No \\
\hline
\end{tabular}

TG, triglycerides; HDL, high-density lipoprotein; IFG, impaired glucose tolerance; NASH, nonalcoholic steatohepatitis (diagnosed on ultrasound). Female teenagers (\#1-3) described by Majithia et al. ${ }^{11)}$ and patient \# 4 is our index case.

Reference values: TG, 0-149 mg/dL; glucose, 70-100 mg/dL; insulin, 3-20 $\mu \mathrm{U} / \mathrm{mL}$; HbA1c, 4\%-5.7\%.

dextrose to maintain euglycemia. Insulin can reduce TG level by $40 \%$. In conjunction with fasting, this approach can effectively lower values by $80 \%$ in the first 24 hours of treatment. ${ }^{14)}$ Heparin, which releases endothelial lipoprotein lipase, has been used without clear benefit in HTG. Heparin has been reported to have short term effects and can increase the risk of bleeding in cases of acute pancreatitis. ${ }^{15)}$ Our patient's TG level was well controlled as she maintained a strict diet. Fenofibrate appeared to have an additive effect as it acts through the PPAR $a$ receptors and decreases the hepatic production of very low density lipoprotein. Additionally, at 4 g per day in adults, omega 3-fatty acids have an adjunctive TG lowering effect in HTG.

Our patient experienced an earlier onset of diabetes than typically seen in FPLD3. Research has suggested that development of diabetes in patients with FPLD is linked to excess subcutaneous fat accumulation in the head and neck region, beginning at puberty, ${ }^{16)}$ and that individuals that harbor pathogenic variants of PPARG with reduced function in adipocyte differentiation have an estimated sevenfold increased risk of T2DM. When Hegele et al. ${ }^{12)}$ compared the phenotypes of pathogenic PPARG (FPLD3, n=8) and LMNA (FPLD2, n=51) variants, they found less adipose tissue loss, greater insulin resistance, and earlier development of diabetes (36 years vs. 41 years) in PPARG subjects. These subjects had worse hypertension and earlier presentation of polycystic ovary syndrome (PCOS), hepatic steatosis, and lower adipocytokines (leptin and adiponectin). An additional mechanism might account for the worse dysmetabolic phenotype in PPARG subjects that cannot be explained by the loss of adipose tissue. Thiazolidinediones (TZDs), a class of synthetic PPAR $\gamma$ agonists, promote adipogenesis and improve insulin sensitivity, which supports their therapeutic use as insulin sensitizers in patients with diabetes in FPLD3. Missense variants in PPARG are estimated to occur in 1/500 of cases, and the effects of synthetic ligands such as TZDs and tyrosine agonists on PPAR $\gamma$ receptors depend on the specific variant. ${ }^{17-19)}$ Agostini suggested a pharmacogenetic approach to treatment with TZDs and reported that some mild loss-of-function variants could be rescued in vitro by PPAR $\gamma$ agonists. ${ }^{20)}$ In contrast, Savage et al. ${ }^{17)}$ reported that severe loss-of-function $P P A R G$ pathogenic variants were not associated with clear therapeutic benefits for TZDs. Prior to initiation of piogliotazone, our patient was lost to follow up.

The c.452A>G p.Tyr151Cys pathogenic variant has been reported to cause FPLD. ${ }^{6,7)}$ This tyrosine-to-cysteine substitution is located in the region of the PPARG gene that encodes the DNA binding domain. This variant reduced DNA binding and reduced transcriptional activity, although direct dominant negative activity was absent. The second variant (c.1003G $>C$ p.Val335Leu), initially reported by the analytical laboratory as a variant of uncertain significance, was classified by Majithia et al. as benign ${ }^{8)}$. Visser et al. ${ }^{6}$ described the first case of FPLD caused by the $\mathrm{Y} 151 \mathrm{C}$ variant using the definition of severe insulin resistance (insulin requirement $\geq 100$ units/day and $\left.\mathrm{BMI} \leq 27 \mathrm{~kg} / \mathrm{m}^{2}\right)$ in 2,500 nonobese adults with T2DM. The case was a 61-year-old European woman with a history of T2DM with onset at 49 years of age, with severe insulin resistance that required insulin at dose of 142 units/day, severe HTG with pancreatitis, hypertension, cardiovascular disease, and excess subcutaneous fat on the face, neck, trunk, and abdomen with lack of subcutaneous fat on the extremities. Akinci et al. ${ }^{7)}$ reported the p.Tyr151Cys variant in Turkish kindred (2 families). The first case was a 24 -year-old female diagnosed with HTG at 15 years and diabetes at 22 years, during which she experienced metabolic complications including proteinuria, hepatic steatosis, and PCOS. There were 4 affected members in the second kindred. The proband was a 28 -year-old female with new onset diabetes, HTG, and fat loss noted at 15 years of age. The mother was insulin dependent and the maternal aunt and brother had HTG. A case series of PPAR $\gamma$ mutations described by Akinci et al. ( $\mathrm{n}=7,77 \%$ female predominance) indicated that the average age was 28 years (range, $25-45$ years); BMI 24 $\mathrm{kg} / \mathrm{m}^{2}\left(22-25 \mathrm{~kg} / \mathrm{m}^{2}\right)$, average blood glucose 113 (92.5-145), and $\mathrm{HbAlc} 6 \%(5.5 \%-7.4 \%)$. All subjects had diabetes and/or prediabetes, average TG level was $228 \mathrm{mg} / \mathrm{dL}$ (range, 178-1,122 $\mathrm{mg} / \mathrm{dL})$, and leptin was $5.5 \mathrm{mg} / \mathrm{dL}(3-8 \mathrm{mg} / \mathrm{dL})$. Hepatic steatosis was noted in $89 \%$ of cases, nephropathy was observed in $56 \%$, PCOS was noted in all female patients, and fat loss was limited to the extremities. On presentation, our patient had severe HTG higher than those described by Akinci et al. ${ }^{7)}$ She showed excessive fat on her face and neck, which was not noted in the subjects described by Akinic et al. ${ }^{7)}$ and could explain her severe insulin resistance and rapid progression to diabetes.

In conclusion, PPARG pathogenic variants should be considered in nonobese children and adolescents presenting with severe HTG and insulin resistance. Clinical acumen can help identify subtle fat loss to trigger additional testing to determine the cause of FPLD, including PPARG. Treatment with PPARy 
agonist TZDs should be considered because this drug class promotes adipogenesis and improves insulin sensitivity in these patients. In addition to following the metabolic and clinical parameters, delineating the changes in fat distribution with whole body MRI pre- and post-TZD can provide meaningful evidence of therapeutic efficacy.

\section{Ethical statement}

The study was provided by the Institutional Review board at New York University School of Medicine. The study met all the ethical standards as required in the study of human subjects.

\section{Conflict of interest}

No potential conflict of interest relevant to this article was reported.

\section{Acknowledgments}

The authors would like to thank Dr. Robert Hegele, Director, Blackburn Cardiovascular Genetics Laboratory, at the Robarts Research Institute for performing the genetic testing and Dr. Ambika Ashraf for her guidance in clinical management of the patient.

\section{Funding}

This research received no specific grant from any funding agency in the public, commercial, or not-for-profit sectors.

\section{References}

1. Peters JM, Barnes R, Bennett L, Gitomer WM, Bowcock AM, Garg A. Localization of the gene for familial partial lipodystrophy (Dunnigan variety) to chromosome 1q2122. Nat Genet 1998;18:292-5.

2. Barroso I, Gurnell M, Crowley VE, Agostini M, Schwabe JW, Soos MA, et al. Dominant negative mutations in human PPARgamma associated with severe insulin resistance, diabetes mellitus and hypertension. Nature 1999;402:880-3.

3. Gandotra S, Le Dour C, Bottomley W, Cervera P, Giral P, Reznik Y, et al. Perilipin deficiency and autosomal dominant partial lipodystrophy. N Engl J Med 2011;364:740-8.

4. Spiegelman BM. PPAR-gamma: adipogenic regulator and thiazolidinedione receptor. Diabetes 1998;47:507-14.

5. Nawrocki AR, Rajala MW, Tomas E, Pajvani UB, Saha AK, Trumbauer ME, et al. Mice lacking adiponectin show decreased hepatic insulin sensitivity and reduced responsiveness to peroxisome proliferator-activated receptor gamma agonists. J Biol Chem 2006;281:2654-60.

6. Visser ME, Kropman E, Kranendonk ME, Koppen A, Hamers N, Stroes ES, et al. Characterisation of non- obese diabetic patients with marked insulin resistance identifies a novel familial partial lipodystrophyassociated PPARgamma mutation (Y151C). Diabetologia 2011;54:1639-44.

7. Akinci B, Onay H, Demir T, Savas-Erdeve S, Gen R, Simsir IY, et al. Clinical presentations, metabolic abnormalities and end-organ complications in patients with familial partial lipodystrophy. Metabolism 2017;72:109-19.

8. Majithia AR, Flannick J, Shahinian P, Guo M, Bray MA, Fontanillas P, et al. Rare variants in PPARG with decreased activity in adipocyte differentiation are associated with increased risk of type 2 diabetes. Proc Natl Acad Sci U S A 2014;111:13127-32.

9. Richards S, Aziz N, Bale S, Bick D, Das S, Gastier-Foster J, et al. Standards and guidelines for the interpretation of sequence variants: a joint consensus recommendation of the American College of Medical Genetics and Genomics and the Association for Molecular Pathology. Genet Med 2015;17:405-24.

10. Broekema MF, Savage DB, Monajemi H, Kalkhoven E. Gene-gene and gene-environment interactions in lipodystrophy: lessons learned from natural PPAR $\gamma$ mutants. Biochim Biophys Acta Mol Cell Biol Lipids 2019;1864:715-32.

11. Majithia AR, Tsuda B, Agostini M, Gnanapradeepan K, Rice R, Peloso G, et al. Prospective functional classification of all possible missense variants in PPARG. Nat Genet 2016;48:1570-5.

12. Hegele RA, Ginsberg HN, Chapman MJ, Nordestgaard BG, Kuivenhoven JA, Averna M, et al. The polygenic nature of hypertriglyceridaemia: implications for definition, diagnosis, and management. Lancet Diabetes Endocrinol 2014;2:655-66.

13. Berberich AJ, Ziada A, Zou GY, Hegele RA. Conservative management in hypertriglyceridemia-associated pancreatitis. J Intern Med 2019;286:644-50.

14. Henderson SR, Maitland R, Mustafa OG, Miell J, Crook MA, Kottegoda SR. Severe hypertriglyceridaemia in Type 2 diabetes mellitus: beneficial effect of continuous insulin infusion. QJM 2013;106:355-9.

15. Näsström B, Olivecrona G, Olivecrona T, Stegmayr BG. Lipoprotein lipase during continuous heparin infusion: tissue stores become partially depleted. J Lab Clin Med 2001;138:206-13.

16. Haque WA, Oral EA, Dietz K, Bowcock AM, Agarwal AK, Garg A. Risk factors for diabetes in familial partial lipodystrophy, Dunnigan variety. Diabetes Care 2003;26:1350-5.

17. Savage DB, Tan GD, Acerini CL, Jebb SA, Agostini M, Gurnell M, et al. Human metabolic syndrome resulting from dominant-negative mutations in the nuclear receptor peroxisome proliferator-activated receptor-gamma. Diabetes 2003;52:910-7.

18. Francis GA, Li G, Casey R, Wang J, Cao H, Leff T, et al. Peroxisomal proliferator activated receptor-gamma 
deficiency in a Canadian kindred with familial partial lipodystrophy type 3 (FPLD3). BMC Med Genet 2006;7:3.

19. Demir T, Onay H, Savage DB, Temeloglu E, Uzum AK, Kadioglu P, et al. Familial partial lipodystrophy linked to a novel peroxisome proliferator activator receptor $-\gamma$ (PPARG) mutation, H449L: a comparison of people with this mutation and those with classic codon 482 Lamin A/C (LMNA) mutations. Diabet Med 2016;33:1445-50.

20. Agostini M, Schoenmakers E, Beig J, Fairall L, Szatmari I, Rajanayagam $\mathrm{O}$, et al. A pharmacogenetic approach to the treatment of patients with PPARG mutations. Diabetes 2018;67:1086-92. 